\title{
Correspondence
}

\section{The Westminster Hospital coronary unit}

SIR-I have read with interest Dr Thurston's article (Postgrad. med. J., 1969, 45, 163) reporting the experience of the Westminster Hospital Coronary Unit and his findings closely parallel ours at St Mary's Hospital.

I would take issue with him over the suggestion of a trial of flying squad ambulances carrying means of resuscitation. He adduces some support for this in that during a similar period of time 435 cases of sudden death due to coronary thrombosis were reported to the Westminster Coroner.

The population (excluding commuters) living in the area of the Westminster Coroner is approximately two million so this is a surprisingly small number. In the same area there are a large number of hospitals and it would be better to set up and staff coronary units in there rather than have new lavishly equipped centres with valuable trained staff tied down in the flying squad ambulances and unavailable for the care of the much more likely to be saved inpatient.

It would be interesting to know the number of cardiac arrests occurring on arrival of or during transport in the ambulance as it would be these patients who would be potentially saved by a flying squad.

The most important aspect of this problem is how the flying squad would be summoned. If it was the patient, many true cases would delay and it would also be at the beck and call of every cardiac neurotic. If it is the General Practitioner then the same delays as exist now would occur. Another insurmountable difficulty in London is the traffic congestion.

I would suggest that the setting up of more coronary units in district hospitals, possibly with the rotation of trained medical and nursing staff from the larger centres to them and closer liaison with their local General Practitioners, may be a way of reducing the mortality of cases of myocardial infarction that never reach hospital.

\section{Senior Medical Registrar, St Mary's Hospital, \\ London, W.2.}

We have shown this letter to Dr Thurston, who replies as follows:
SIR-Basically I agree with Dr Everest's comments. Ideally, there would be many more Coronary Intensive Care Units now that the value of these has been established, the limiting factors being the cost and the staff to run them.

The cost to the Health Service related to the number of patients cured has not prevented several other developments from going ahead. I refer in particular to the screening of children for phenylketonuria; renal dialysis and transplantation; heart transplantation and other projects which are very expensive per life saved.

My suggestion was for a single trial flying squad based in central London. This might be expensive to set up but would not need many staff to serve several million potential patients in this highly populated area. Ambulances with lights and sirens going get through congested traffic at a speed which surprises the frustrated private motorist. The return journey to hospital can be made at leisure because monitoring devices, trained staff and defibrillator are all in the ambulance. This is the essential advantage of the flying squad.

The catecholamine production and possible subsequently increased risk of ventricular fibrillation must almost certainly be increased in a patient alarmed by the speed and noise with which he should be rushed to hospital at present although I do not know the number of cardiac arrests occurring on arrival of, or during transport in, the ambulance.

I envisaged the general practitioner summoning the ambulance (as in Belfast) and not the patient. If an official directive were sent to general practitioners in the relevant catchment area, much delay would be avoided as they could then contact the team at a moment's notice by a telephone designated for that sole purpose. This would obviate the need (all too familiar to general practitioners) of telephoning round hospitals or the Emergency Bed Service for a bed and waiting to speak to duty medical registrars etc.

Surely, this scheme which has saved several lives in Belfast is at least worth a trial in London.

Medical Registrar, Coronary Intensive Care Unit,

JOHN THURSTON Westminster Hospital,

London, S.W.1. 